\title{
El turismo alternativo: una opción para el desarrollo local en dos comunidades indígenas de Baja California
}

\author{
Nora L. Bringas R." \\ J. Igor Israel GonzÁlez A.**
}

\begin{abstract}
In this article, we study the relationship between local development, alternative tourism and sustainability. The analysis starts from the 'discontentment' of two indigenous communities from Baja California about the 'exploration of alternative tourism as a mean of development. It is important to clarify that the cases studied here are not a posteriori evaluation to implement a touristy project. We analyse the 'creation' of such a project: origin, mobility and involvement of several agents with different action mechanisms, capacities, interests and influence areas. This allows us to offer, as a context, some essential elements for structuring policies for alternative tourism within the frame of sustainability.
\end{abstract}

Keywords: indigenous communities, local development, sustainability, alternative tourism, elements of tourist politics.

\section{Resumen}

Se analiza la relación entre desarrollo local, turismo alternativo y sustentabilidad. Nuestro punto de partida radica en la inquietud proveniente de dos de las comunidades indígenas de Baja California, México, la cual refiere a la exploración del turismo alternativo como una vía para el desarrollo. Aclaramos que los casos que analizamos no se refieren a una evaluación a posteriori del desarrollo de un proyecto de corte turístico. Más bien, este trabajo se enfoca en analizar la puesta en marcha de dicho proyecto: el surgimiento, la movilización y el involucramiento de nuevos actores con variados mecanismos de actuación y distintas capacidades, intereses y ámbitos de influencia. Esto nos permite ofrecer, a manera de contexto, algunos elementos necesarios para la estructuración de políticas para un turismo de corte alternativo enmarcadas en la sustentabilidad.

Palabras clave: comunidades indígenas, desarrollo local, sustentabilidad, turismo alternativo, elementos de política turística.

* El Colegio de la Frontera Norte. Correo-e: nbringas@colef.mx

** Estudiante del Programa de Doctorado en Ciencias Sociales, El Colegio de Jalisco. Correo-e: jiigonzaleza@hotmail.com 


\section{Introducción}

Es innegable que en la actualidad los temas relacionados con desarrollo sustentable se han convertido en un campo de estudio fértil y legítimo. A ello se debe que conceptos como el de sustentabilidad hallan encontrado eco a escala global, a tal grado que esta noción se ha filtrado tanto en los ámbitos políticos y académicos como en las distintas esferas de la sociedad civil, aunque cabe mencionar que esta idea ha sido menos exitosa desde el punto de vista de sus logros concretos (Butler, 1998). No obstante, como veremos a lo largo de este texto, pareciera que es en la actividad turística donde mejor pudieran ejemplificarse algunos de sus aciertos.

En este sentido, las experiencias exitosas de desarrollo sustentable y las mejoras en torno a la calidad de la vida y al ambiente han resultado ser más la excepción que la regla. Sin embargo, tratando de recuperar lo positivo de esta nueva forma de ver el mundo, se observa que en los niveles locales se gestan oportunidades para el surgimiento de nuevos actores y nuevas actuaciones en términos de participación e involucramiento por parte de la sociedad civil en los procesos de desarrollo. Así, las comunidades indígenas, al igual que muchos otros grupos minoritarios hasta hace muy poco olvidados, ahora son parte esencial de esta reinvención por la que atraviesa la idea del desarrollo. Sin duda, uno de los elementos recurrentes para potenciar el desarrollo de tales comunidades se refiere al aprovechamiento turístico de los recursos naturales y culturales inherentes a éstas.

A lo anterior subyacen dos supuestos fundamentales. En el primero se señala que el desarrollo es un proceso social horizontal, dinámico y complejo, y no una serie de etapas por las cuales es necesario transitar. El segundo refiere a que la sustentabilidad consiste más en un marco participativo para la acción, y no un estado de desarrollo que pueda ser alcanzado. Aceptar lo anterior implica la necesidad de potenciar y promover el surgimiento de nuevos escenarios, actores y actuaciones en los ámbitos locales. En este contexto, la idea del desarrollo sustentable atraviesa de manera crucial a la actividad turística. A la par del modelo tradicional de sol y playa emergen nuevas formas de hacer y pensar el turismo, desde las cuales se aprovechan los recursos culturales y naturales de manera 'sustentable'. Estas nuevas formas han sido denominadas por los estudiosos del tema como turismo alternativo. 
Situados en este marco de referencia, en este trabajo ilustramos nuestros argumentos con base en el estudio de dos comunidades indígenas nativas de Baja California (B.C.), México: San José de la Zorra y San Antonio Nécua, ambas localizadas en la parte noroeste de la mencionada entidad federativa. Cabe mencionar que existen dos factores fundamentales que inciden en la elección de estas dos comunidades. El primero de ellos consiste en que la iniciativa de explorar el aprovechamiento de los recursos naturales y culturales -en cuanto a un turismo de corte alternativo, como lo es el ecoturismo-proviene de las mencionadas comunidades. Esto es crucial para el mayor o menor éxito de una propuesta de este tipo, ya que se sabe que la 'imposición vertical y externa' de proyectos de desarrollo tiene altas probabilidades de fracaso. El segundo se refiere a la cercanía geográfica que presentan ambas comunidades con respecto a zonas de un notable flujo turístico, tal como es el Puerto de Ensenada y el Valle de Guadalupe, este último reconocido internacionalmente por ser la principal región productora de vino de México.

Cabe mencionar que hemos situado este texto bajo un marco como el planteado en los párrafos anteriores. Para ello lo dividimos en tres grandes secciones. En la primera de ellas se plantean algunos elementos conceptuales básicos en torno a la relación entre desarrollo local y turismo alternativo -todo ello bajo el marco de la sustentabilidad-. En la segunda parte se presentan, a grandes rasgos, algunos de los elementos que conforman el proceso que se genera a raíz de la posible articulación entre turismo y desarrollo en el ámbito territorial de las dos comunidades estudiadas, ya que ello implica la movilización y el involucramiento de una serie de actores con variados mecanismos de actuación y distintas capacidades, intereses y ámbitos de influencia. Finalmente, en la tercera parte se ofrecen, a manera de contexto, algunos elementos necesarios para la estructuración de políticas para un turismo de corte alternativo.

\section{Desarrollo local, turismo alternativo y sustentabilidad: algunos planteamientos conceptuales}

\subsection{Nuevos enfoques: el desarrollo local}

En la actualidad, la sustentabilidad es una de las ideas que ha tenido mayor presencia en buena parte de las formaciones discursivas que marcan los distintos ámbitos de la vida social, cultu- 
ral, política y económica de nuestro tiempo. La relación entre turismo y sustentabilidad ofrece un panorama en el que aquél pudiera constituirse en una de las vías más eficaces para lograr detonar procesos de desarrollo, enfatizando la agencia de las poblaciones locales. ${ }^{1}$ Específicamente, nos referimos con lo anterior al aprovechamiento por parte de las mencionadas poblaciones locales de los recursos naturales y culturales mediante un 'turismo de corte alternativo'. A escala nacional, esta forma de turismo se perfila como una opción viable para el desarrollo de algunas de las etnias que habitan el territorio mexicano. De hecho ya existen ejemplos exitosos de proyectos productivos donde el ecoturismo ha sido el principal eje de desarrollo, tal es el caso de Punta Laguna en la península de Yucatán, los Altos de Chiapas y Mazunte en Oaxaca (Ceballos, 1998; Zeppel, 1998). ${ }^{2}$

Ahora bien, en los modelos que rigen actualmente los destinos de la mayor parte de los países de América Latina se ha enfatizado el plano macroeconómico de las grandes cifras. Así, el desarrollo ha sido concebido de manera vertical y centralizada, 'desde arriba': se ha confundido desarrollo con crecimiento. ${ }^{3}$ En este tenor, se privilegian los agregados, se enfatiza el incremento de cifras como el PIB, se busca el control y equilibrio de las tasas y los índices, entre otros; al abstraerse de la preocupación por distribuir de manera equitativa los productos generados por el crecimiento económico, el desarrollo es equiparado, en última instancia, con el crecimiento de las grandes cifras.

${ }^{1}$ En ocasiones, la idea de 'agente' se utiliza para referirse a una persona que actúa en lugar de otra (i. e. literatura económica, teoría de juegos). Para este trabajo, retomamos la idea planteada por Sen (2000: 15), desde la cual, la noción de agente alude a “[...] la persona que actúa y provoca cambios cuyos logros pueden juzgarse en función de sus propios valores y objetivos, independientemente de que los evaluemos o no también en función de algunos criterios externos”. Así visto, la agencia sería la capacidad de actuación que ostenta el actor.

${ }^{2}$ La comunidad rural de Mazunte se localiza en la costa de Oaxaca; ésta recibió apoyo y asesoría de una Asociación Civil (Ecosolar) para echar a andar proyectos productivos sustentables, uno de los cuales ha sido el ecoturismo. Bajo esta noción se erigió un pueblo turístico con casas construidas con materiales típicos de la región y se introdujeron tecnologías ecológicas como sistemas de tratamiento de aguas, talleres de salud, nutrición, turismo, cocina, entre otros lo que sirvió como detonador para explorar alternativas de empleo que permitieran sobrevivir a la población local después de que se decretó la veda de la caza de la tortuga. Simultáneamente se crearon otros proyectos sustentables como la Fábrica de Cosméticos Naturales, que fue financiado por The Body Shop International (véase <http://www.laneta.apc.org/mazunte/home.htm>).

${ }^{3}$ Al respecto, Jiménez Herrero (1997:48) retoma las ideas planteadas por Daly, para señalar que 'crecer' quiere decir aumentar de tamaño con adición o asimilación de material, mientras que 'desarrollar' implica expandir potencialidades, llegar de manera gradual a un estado más completo. 
En este contexto, autores como Sen (2000: 15) han señalado la necesidad de un cambio de enfoque, ya que estas perspectivas economicistas han creado una gran paradoja. Por una parte, nuestro mundo está caracterizado por una 'opulencia sin precedentes'; además de los cambios en el terreno de lo económico, durante el siglo Xx se ha consolidado el sistema de gobierno democrático y participativo, en tanto modelo superior de organización política. Vivimos más que antes, y el mundo está más vinculado que nunca, tanto desde el punto de vista de comunicaciones y comercio, como en el campo de las ideas. No obstante, la otra cara de la moneda muestra que también vivimos en un mundo de privaciones, miseria y opresión. Persiste la pobreza, existen necesidades básicas insatisfechas, hambrunas, violación de las libertades individuales, empeoramiento de las amenazas sobre el entorno natural, vulnerabilidad social, etc. Lo anterior ocurre tanto en los países ricos como en los pobres.

Así, la superación de los problemas descritos constituye una parte fundamental del "ejercicio de una nueva perspectiva acerca del desarrollo" (Sen, 2000: 16). Los argumentos del mencionado autor resultan importantes y novedosos en la medida en que reconocen el papel fundamental que desempeña la agencia individual en la resolución de tales problemas. En este sentido, hay una clara complementariedad entre agencia individual y las instituciones sociales: esto es, entre los ámbitos macro-estructurales y micro-interpretativos del desarrollo. Así visto, el desarrollo consiste en otorgarle a los individuos más y mejores oportunidades para ejercer su 'agencia razonada'. Lo anterior obliga a analizar de manera integral las actividades económicas y sociales en las que intervienen las distintas instituciones de la vida social, así como el papel de muchas 'agencias interactivas' o instituciones y actores locales. Como veremos más adelante, lo anterior resulta crucial para la estructuración de políticas de desarrollo (Sen, 2000: 16-20).

En los argumentos planteados por Sen (2000) encontramos un marco adecuado para situar el cambio que se experimenta en la noción de desarrollo. Más que un aspecto macroestructural, éste es planteado como un incremento de la participación de los actores locales en los procesos de desarrollo. Ello redundará en, por ejemplo, mayores capacidades económicas y políticas. Pero ¿cómo articular los argumentos anteriores, de corte más general, con la perspectiva de desarrollo local? 
Algunos autores señalan que las bases principales para el crecimiento económico de las localidades consisten en factores como el espíritu de empresa local y las instituciones financieras locales (Ferrás y Paredes, 1999: 87). Como se observa, este planteamiento hace énfasis en los actores locales y en sus capacidades. Con ello se le agrega un componente territorial y específico a la idea del desarrollo: el punto focal es lo local. Otra característica de este estilo particular de desarrollo consiste en que lleva implícita una vinculación con la economía de mercado y el modo de producción del capitalismo neoliberal. Es decir, se relaciona estrechamente con 'las capacidades de transformar, reaccionar, promover e introducir que pueden o deben poseer los individuos que conforman una sociedad'. ${ }^{4}$ Es decir, la agencia, desde el punto de vista de Sen (2000). No se está, pues, en desacuerdo con los planteamientos del mercado libre; por el contrario, se apuesta por una vinculación con éste, pero en términos más equitativos.

Autores como Azevedo (1999: 65) han intentado llevar los argumentos anteriores a un ámbito más concreto. Al recurrir a este planteamiento se quiere presentar un panorama sintético sobre las cuestiones críticas vinculadas a la planeación y puesta en marcha de proyectos de desarrollo. Como ya lo señalamos, uno de los factores fundamentales del 'otro desarrollo' radica en el aprovechamiento de los recursos naturales por las localidades que los 'poseen'. El incremento de esta 'libertad' implica la creación de capacidades de gestión local de tales recursos. Así aparece, entonces, otro de los componentes, el ambiental, que perfila un poco más la idea de desarrollo que intentamos elaborar aquí. En este contexto se requiere abordar este concepto desde sus 'desdoblamientos operativos' con base en el binomio 'desarrollo y conservación de recursos naturales'. Así visto, la discusión sobre el desarrollo hace énfasis en el reconocimiento de los desequilibrios de corte social y ambiental, inherentes a los modelos económicos vigentes (sobre todo a partir de la formación del Club de Roma, en 1968). Puede verse, pues, que la idea de sustentabilidad comienza a vincularse fuertemente con la noción de desarrollo.

\footnotetext{
${ }^{4}$ Ferrás y Paredes (1999:87) señalan que el desarrollo local es una estrategia alternativa a la clásica de los 'polos de desarrollo', la cual dominó las políticas publicas de desarrollo regional en las décadas de los sesenta y el setenta. Tales polos eran ciudades elegidas por el poder político para impulsar la localización de industrias. Frente a éstas, el desarrollo local, propio de los años ochenta y noventa, es impulsado desde la base social. Así visto, la comunidad local es la protagonista de su propio desarrollo.
} 
En este sentido, Folch señala que el desarrollo sustentable no es ninguna teoría, sino que más bien constituye un concepto de corte ideológico: una "utopía deseable" (Folch, tomado de Pimienta, 1999: 125). En buena medida, lo anterior ha ocasionado que la idea de sustentabilidad se caracterice por su falta de concreción. A pesar de la vaguedad y abstracción retórica de dicho término, es ineludible apelar a conceptos como los de necesidades, limitaciones, globalidad, equidad, eficiencia, revalorización del papel del medio ambiente, la tecnología, entre otros. A partir de lo anterior, es posible identificar una serie de ángulos en torno al desarrollo sustentable. Estas vertientes son de corte ecológico o ambiental, económico, social y cultural; más adelante se regresará sobre este punto (Pimienta, 1999).

Cabe señalar que la incorporación de un componente ambiental en un proyecto de desarrollo no representa una garantía con relación a la efectividad que tenga en la protección y manejo de los recursos naturales. Desde un punto de vista crítico, cabría preguntarse acerca de cuál es el papel que desempeña la actividad turística en el ámbito del desarrollo local. Santos (1999) ofrece algunas pistas al respecto. Desde una postura crítica a programas como el LEADER o el PRODER, ${ }^{5}$ este autor indica que la mayor parte de los intentos de desarrollo local que fueron -o están por serpuestos en marcha, tienen al turismo como un objetivo prioritario. En este sentido, se espera que dicha actividad se convierta en una base sobre la que se formulen todas las iniciativas que tienen relación con el desarrollo local: promoción y diversificación de las actividades productivas, impulso a los espacios rurales en crisis. En definitiva, se ve al turismo como la gran salvación de un mundo rural en declive (Santos, 1999). Habría pues que señalar que existe el riesgo de convertir a una región o localidad en monodependiente de una actividad altamente estacional como es el turismo. Es por ello que la puesta en marcha de un proyecto que fomente dicha actividad requiere de ir acompañado de programas de diversificación productiva y todo lo que ello implica (Ceballos, 1998).

En este sentido, algunos autores señalan que el desarrollo turístico puede llegar a ser una oportunidad para las comunidades

${ }^{5}$ Santos (1999: 151) ofrece algunos ejemplos de lo anterior. En Castela-León, la cantidad destinada al turismo rural fue de $48.2 \%$ del total de las inversiones de LIDER I. En la sierra norte de Madrid, el turismo concentró 70\% de las inversiones de LEADER I, y $37.5 \%$ de LEADER I. En Cataluña, la cifra dedicada al turismo fue del $44 \%$ del LEADER I. 
locales planteándolo bajo criterios de 'competitividad, autenticidad y sustentabilidad' (Martín et al. 1999: 179). Con respecto a la 'competitividad', la creación de nuevos destinos turísticos debería gestionarse desde y para el territorio y la comunidad que lo habita. Si se entiende al sector turístico como un proceso económico, partiendo de una demanda cada vez más segmentada, la estructura de la oferta debería desprenderse de amenazas o disfunciones (por ejemplo el sobredimensionamiento, los intereses divergentes, la especulación). En lo que se refiere a la 'autenticidad', la comunidad-destino debe configurarse y promoverse mediante: i) una singularidad (por ejemplo conservando las formas de vida tradicionales, hábitos y costumbres locales, además del patrimonio cultural y los valores históricos, ambientales, antropológicos); ii) una integración, es decir, conformándose como producto fundamentado en los atractivos y recursos naturales y culturales, reconociéndose la condición turística a partir de su configuración como un sistema funcional y organizado. Finalmente, con respecto a la 'sustentabilidad', es necesario proteger el medio físico, controlando los impactos (en el medio natural y en el medio construido), así como preservar el medio natural a través de la zonificación y delimitación de los distintos usos de suelo, con protección especial a las áreas más vulnerables.

Hasta aquí hemos discutido que el desarrollo es un proceso horizontal, de incremento de libertades y capacidades de los actores en el ámbito de lo local. Ello implica un distanciamiento con respecto a las visiones tradicionales. Hemos planteado la posibilidad de relacionar esta otra visión del desarrollo con una actividad turística de corte alternativo. Consideramos que uno de los marcos explicativos para las transformaciones que experimenta la idea de desarrollo radica en la noción de sustentabilidad, entendida como un marco 'dinámico' para la acción y no como un 'estado' que pueda ser alcanzado (González, 2000). Por ello, a continuación se revisarán algunas ideas sobre el turismo alternativo, para luego enmarcar nuestros argumentos dentro de los planteamientos básicos de la sustentabilidad. Con ello, pensamos, se hará más explícita la relación entre desarrollo local, turismo alternativo y sustentabilidad.

\subsection{Turismo alternativo}

De manera tradicional, la actividad turística ha sido una de las piezas más dinámicas del escenario mundial. En el año 2001, la 
derrama total mundial generada por las actividades turísticas fue de alrededor de 462.6 billones de dólares, 2.6\% inferior a lo registrado en el año 2000, ello derivado de los ataques terroristas en Estados Unidos (OMT, 2002: 3). De acuerdo con cifras manejadas por SECTUR (2002), en ese mismo año ingresaron a nuestro país 8,400.5 millones de dólares. En relación con el flujo de personas, se tiene que en mismo año se registraron aproximadamente 693.6 millones de turistas alrededor del mundo (OMT, 2002: 2). De este total, México recibió 19.8 millones (seCtUR, 2002).

Todas las proyecciones apuntan que durante el siglo XXI habrá un marcado crecimiento del sector turístico en todos sus aspectos. Cifras de la Organización Mundial de Turismo (OMT) señalan que en el año 2002 se contabilizaron en todo el orbe 714.6 millones de llegadas de turistas internacionales (OMT, 2003) que generaron ingresos del orden de los 474 billones de dólares, lo que significa un aumento de $3.2 \%$ con respecto al año anterior. En cuanto al turismo basado en la naturaleza, se sabe que el ecoturismo es el segmento de mayor crecimiento: se estima que en el plano mundial de viajes éste crece a un ritmo de $20 \%$ anual. Tan sólo en 1998, cerca de 5\% de los visitantes internacionales hicieron un recorrido ecoturístico, lo que se traduce en aproximadamente 30 millones de viajes (OMT, 2001: 95-97).

En la actualidad nadie duda de la relevancia que representa el turismo para México. En el año 2002 este país recibió 100.1 millones de visitantes internacionales, con lo cual se colocó en el octavo lugar en el plano mundial en la atracción de turistas, y en la recepción de divisas captó 8,858 millones de dólares, lo que destaca sus beneficios (SECTUR, 2003). No obstante la importancia que está cobrando el ecoturismo en México, aún no existen estadísticas que confirmen el tamaño del mercado, aunque se sabe que es muy marginal: menos del uno por ciento del total de divisas que entran al país por concepto de turismo (sECTUR, 2001). Se estima que el valor de la demanda anual de ecoturismo y turismo de aventura es superior a los $\$ 750$ millones de pesos, de los cuales $64 \%$ proviene de visitantes internacionales y el restante $36 \%$ del mercado doméstico (sECTUR, 2001)

A pesar de las serias consecuencias que se experimentaron en la actividad turística mundial, a raíz de los atentados del 11 de septiembre de 2001, en Estados Unidos, y las recientes guerras que ese país libró en Afganistán e Irak, dicha actividad seguirá en crecimiento (OMT, 2003). En este sentido, puede decirse que el 
turismo actual es preponderantemente un fenómeno de carácter masivo y estandarizado. ${ }^{6}$

La emergencia del turismo masivo trajo consigo la necesidad de funcionalizar algunos espacios a partir de la construcción de grandes instalaciones, equipamientos y la práctica de ciertas actividades sobre el territorio. Todo este proceso ha tenido efectos inmediatos sobre el entorno donde este fenómeno se implanta y, probablemente por lo espontáneo y acelerado de su surgimiento, en la mayoría de los casos, éste no estuvo sujeto a esquemas de planeación del territorio. Esto explica el tardío interés en reconocer la importancia que ha jugado el turismo en la organización del espacio, lo cual ha traído consecuencias no sólo en el plano territorial, sino también en el económico, socio-cultural, y sobre todo, en el ambiental (Laborde, 1991; Vera Rebollo, 1997).

Sin duda, los elementos emblemáticos característicos del turismo de masas han sido el sol y la playa. Ello explica el hecho de que la mayor parte de los destinos masivos del mundo sean los que se localizan en zonas litorales. Así, el sol y la playa pasan a formar parte del ideal de vacaciones, acentuándose con ello un modelo de consumo basado en la existencia de las cuatro 's', por sus siglas en inglés (Sun, Sea, Sand y Sex), (Callizo, 1991 y Vera Rebollo, 1997). Este tipo de turismo ha jugado un papel importante en la modificación de la organización espacial, que se ha manifestado en el surgimiento y proliferación de centros turísticos en los frentes de mar, producto de viejas inercias y en menoscabo de los asentamientos existentes en áreas adyacentes a la línea de costa, en tierras interiores, como lo es el caso de las comunidades estudiadas.

Ahora bien, el debilitamiento de este modelo tradicional (Vera Rebollo y Monfort, 1994) en algunos países desarrollados ha favorecido el surgimiento de nuevas formas de hacer y pensar el turismo. Hoy, el interés de la actividad turística apunta hacia la búsqueda de un ambiente natural 'sano', un producto turístico

${ }^{6}$ El boom del modelo turístico convencional, también denominado como turismo de masas, tiene su origen a inicios del siglo xx. Dicho modelo representa la democratización de los viajes, ya que hasta antes del advenimiento de medios de transporte, tales como el ferrocarril, el automóvil y posteriormente el avión, el viajar era privilegio únicamente de ciertas élites. No es sino hasta la década de los setenta que el modelo turístico convencional entró en crisis. Debido tanto a las altas concentraciones geográficas de los turistas en espacios determinados, las grandes diferencias culturales entre los anfitriones y los turistas, la marginación social y económica del anfitrión, los efectos ecológicos perniciosos que se derivan de todo ello, como a cambios en los gustos del turista que emerge un modelo alternativo (Urry, 1994: 16-60). 
más auténtico, una mejor distribución de la oferta en el territorio y la incorporación de nuevos espacios para el desarrollo del turismo. De tal forma, se empieza a abordar conceptualmente el territorio con una nueva 'mirada turística': se valora de manera distinta el carácter 'natural' y 'rural' del espacio. Ello amplía las opciones para atraer un turismo 'diferente' hacia áreas tradicionalmente relegadas de la actividad turística. Este es el caso de algunas de las comunidades indígenas que habitan el territorio mexicano. Bajo esta perspectiva, el turismo alternativo es concebido también como un factor para el desarrollo local sustentable, es decir, como un elemento dinamizador para que las áreas rurales obtengan fuentes alternativas de ingresos y no tengan que 'destruir' sus recursos para poder subsistir (Bringas y Ojeda, 2000).

En resumen, el modelo turístico convencional experimenta diversas transformaciones de orden global (Bringas y Ojeda, 2000). Algunos autores señalan que los cambios que atraviesan a la actividad turística indican una transición de un 'turismo viejo', caracterizado por la estandarización, hacia uno completamente 'nuevo' cuya principal singularidad es la flexibilidad (Poon Apud Urry, 1994: 15). Sin embargo, desde nuestra perspectiva, consideramos que más que una transición entre modelos, es posible observar que, paralelo al inevitable crecimiento del turismo convencional, surge un modelo turístico distinto (y complementario): el 'turismo alternativo'. En este sentido, es posible definir este tipo de turismo, de manera general, como aquel que es coherente y consistente con los valores sociales, naturales y comunitarios que le permiten tanto al turista como al residente local disfrutar de una interacción fundamentada en una serie de experiencias compartidas entre ambos (Smith y Eadington, 1992:1 y Pearce, 1992: 15-18).

Sin embargo, para que el turismo transite por la ruta de la sustentabilidad y no se transforme en una forma de 'neo-colonialismo' se tiene que “[...] desarrollar y mantener una comunidad o ambiente, de tal forma y a tal escala que permanezca viable en un periodo de tiempo indefinido y que no degrade o altere el ambiente (humano y físico) circundante, a tal grado que impida el éxito y desarrollo del bienestar de otras actividades en el proceso" (Butler, citado en Wall, 1997: 29).

Las divergencias entre el turismo convencional y el alternativo son bastantes: el acelerado desarrollo del primero contra el crecimiento gradual y optimización del espacio en el segundo; otro distintivo notable es el cambio que ocurre en relación con la 
inversión, pues de requerirse grandes montos en infraestructura y equipamiento para dar cabida a las 'hordas doradas' de turistas que requieren de cierto confort y pasividad en las comunidades receptoras, frente al modelo alternativo que se orienta más hacia la inversión en capital humano y un comportamiento activo del turista. En última instancia, el enfoque que subyace a tales cambios indica, por una parte, la preocupación de que las comunidades receptoras del flujo turístico resulten beneficiadas a partir de éste. Por otro lado, se intenta minimizar en la medida de lo posible los costos sociales y culturales que la actividad turística genera. (Vera Rebollo, 1997; Swarbrooke, 1998; Urry, 1994).

Así visto, dentro del marco de cambios y transformaciones que experimenta el turismo, éste adopta nuevas formas, teniendo como parámetros fundamentales los siguientes: i) viabilidad económica e institucional; ii) sensibilidad hacia los entornos socioculturales, y iii) respeto hacia los entornos naturales.

Finalmente, las transformaciones que experimenta la actividad turística en la actualidad pueden ser vistas, en cierta medida, como resistencia y contraparte a la serie de procesos que coadyuvan a la unificación y la uniformidad de los espacios históricos, sociales, políticos y culturales. Es decir, aparece una tendencia, que si bien no es generalizable, sí permite señalar que los 'otros turismos' representan un vehículo para el establecimiento de nuevos vínculos del ser humano para con su entorno, la reafirmación de las identidades colectivas, y el reconocimiento las diferencias, de los otros, como actores con distintas capacidades para dirigir los procesos de cambio, incidir en la gestión de los mismos y ejercer su influencia en las dimensiones políticas, sociales, culturales y económicas en la esfera local. Lo anterior tiene detrás de sí una serie de cambios profundos en la noción de desarrollo, a los cuales aludimos de manera breve en la primera sección de este apartado.

\subsection{Algunos planteamientos relacionados con la noción de la sustentabilidad}

A partir de la década de los años ochenta se ha venido hablando de un concepto que es relativamente nuevo, que señala la necesidad de un cambio en relación con la noción de desarrollo: la sustentabilidad. Dicho término fue utilizado por primera vez en 1987, dentro de un estudio realizado por la Comisión Mundial para el Medio Ambiente, llevada a cabo por la Organización de las Naciones Unidas (ONU), en donde entre otras cosas, se llegó a 
la conclusión de que era necesario tener un cambio de fondo en el enfoque del desarrollo, ya que el planeta y todos sus sistemas ecológicos estaban sufriendo daños graves e irreversibles, debido a que los modelos tradicionales de desarrollo están basados en buena medida en visiones de corto plazo y de recursos ilimitados. ${ }^{7}$

No obstante, la idea de lo que posteriormente se denominaría desarrollo sustentable fue popularizada años antes por la Unión Internacional para la Conservación de la Naturaleza y los Recursos Naturales (IUCN, por sus siglas en inglés), en la Estrategia mundial de conservación, propuesta en 1980. Dicha idea planteaba que el desarrollo debería tomar en cuenta las interacciones de los sistemas sociales, culturales, ecológicos, y económicos. Desde esta perspectiva, coincidimos con las críticas de algunos autores cuando señalan que el desarrollo sustentable es un producto conceptual, cuya construcción es netamente racional. Además, en dichas críticas se argumenta que en su objetivo, en su práctica y en su marco disciplinario, la sustentabilidad es el resultado de un enfoque en el que se privilegian los componentes económicos del desarrollo (Aguirre Muñoz, 1998: 151).

En la actualidad, puede decirse que el debate que gira en torno de la sustentabilidad se enfoca en la 'intercambiabilidad' que presentan los aspectos económicos y los aspectos ambientales de la sociedad. Mejor dicho, en tal debate se discute el supuesto de si el capital natural y el capital construido son intercambiables entre sí. En términos generales, este debate se ha denominado 'sustentabilidad débil contra sustentabilidad fuerte' (Hediger, s.f.: 1120-1143; Ayres, et al., s.f.). En este sentido, se presenta una 'sustentabilidad débil' cuando el desarrollo lleva aparejada una explotación cuasi-devastadora de los recursos naturales. Aunque subyace a ello el supuesto de que esta explotación del capital natural puede ser recompensada (intercambiada) por el capital económico que aquélla genera. Este supuesto indica que existe la posibilidad de reemplazar el capital natural con capital "hecho por el ser humano" (Gunawardena, 2002). No hay una equidad ambiental, ni se preservan los recursos naturales; pero los benefi-

\footnotetext{
${ }^{7} \mathrm{Al}$ respecto, cabe señalar que en 1972, en el contexto de la Conferencia Mundial sobre el Medio Ambiente organizada por la onu, emerge el Programa de las Naciones Unidas para el Medio Ambiente (PNUMA). Posteriormente, la discusión en torno a tales aspectos perdió fuerza y no fue sino hasta 1987 que, plasmado en el informe presentado a la asamblea de las Naciones Unidas, comúnmente conocido como Nuestro Futuro Común o el Informe Brundtland, se presenta de manera explícita lo que se entenderá como desarrollo sustentable.
} 
cios generados por la actividad económica compensarían los costos ecológicos de dicha actividad.

Por otra parte, una 'sustentabilidad fuerte' sería aquella en la que el desarrollo no implica la disminución de las oportunidades de vida: se conserva el stock de capital humano, la capacidad tecnológica, los recursos naturales y la equidad ambiental (Brekke citado en Ayres, et al., s.f.). Bajo el criterio de la sustentabilidad fuerte se supone que los recursos naturales representan insumos esenciales para el proceso de producción, y no pueden ser sustituidos o intercambiados por capital construido, económico o humano. En esta postura se sitúan movimientos tales como el de Deep Ecology, los cuales consideran que todo componente o subsistema del ambiente natural debe ser preservado. En última instancia, se considera que ciertas partes de los ecosistemas son únicos y algunos procesos (de daño) ecológico son irreversibles. Esta perspectiva también se relaciona con aquellos elementos de los ecosistemas cuya función es crítica en el sentido que 'prestan servicios' únicos o su valor de uso es irremplazable. Para el caso de la actividad turística, algunos elementos que encajarían dentro de esta categoría son los arrecifes de coral, las áreas naturales protegidas, entre otros.

Resulta evidente que la discusión acerca de 'lo fuerte y lo débil' de la sustentabilidad está permeada por una 'aura verde', por lo que se privilegian los aspectos ecológico-económicos de la misma; con ello se obvian aspectos político-institucionales y socioculturales, los cuales son parte fundamental de la idea del desarrollo (sustentable). Esto es así debido a que la concepción del desarrollo desde la cual parte dicho debate es 'estática', es decir, supone a la sustentabilidad como un estado (del desarrollo) que puede ser alcanzado (y no como un proceso dinámico, social, horizontal y complejo). Por ello, situamos este documento en una perspectiva diferente, la cual permite aportar elementos para la construcción de políticas públicas más integrales. Así, pensamos en la sustentabilidad en términos de un marco comprensivo/interpretativo para la acción colectiva, compuesto por dimensiones ecológicas, económicas, sociales, culturales y políticas. Además, dicho marco no es de corte universalista y totalizante, sino flexible, ya que tiene arreglo a esferas temporales y espaciales específicas (por ejemplo contextos situacionales de las comunidades indígenas analizadas en este documento).

Sea como fuere, el desarrollo, adscrito al marco ideal del deber ser planteado por la sustentabilidad tiene como esencia sa- 
tisfacer "las necesidades del presente sin comprometer la capacidad de generaciones futuras de satisfacer sus propias necesidades" (Smil, 1993:156). Esta concepción influyó sobre lo que se entendió durante mucho tiempo como desarrollo; es decir, como el crecimiento económico sin importar la explotación irracional de los recursos culturales y naturales ni la distribución de los beneficios obtenidos a raíz de ese crecimiento -sustentabilidad débil- pero considera, además, la posibilidad de la acción colectiva local en pos del desarrollo; y los factores de ello son de orden sociocultural y político-institucional, por lo cual no basta la discusión de la sustentabilidad desde el punto de vista de débil vs. fuerte.

Lo anterior, entre otras cosas, indica un cambio en el papel que desempeña cada uno de los actores en su propio ámbito de acción. La gestión y planificación requieren de una relación de vinculación local y externa $-y$ no de dependencia-, es decir, incrementos de las libertades locales, en los términos planteados por Sen (2000). Es fundamental reconocer como un derecho y obligación de cada colectividad territorial, de cada pueblo, de cada comunidad, el promover las acciones capaces de generar las condiciones necesarias para el desenvolvimiento de las mismas. Así visto, en los debates que giran en torno al desarrollo sustentable, uno de los elementos clave es el necesario involucramiento y la participación activa y constante de las comunidades en dicho proceso. Y ello sólo es posible abordarlo desde una dimensión político-institucional.

Podemos afirmar, pues, que en el desarrollo sustentable se destacan las principales responsabilidades que la humanidad tiene para con el planeta, y en general, la necesidad de realizar cualquier actividad dentro de un marco de sustentabilidad económica, social y cultural. Tal como lo señala Jiménez:

[...] la sustentabilidad refiere la función de la población en el aprovechamiento-uso-depredación de los recursos que, frecuentemente, se vincula con las condiciones socioeconómicas y culturales específicas de las localidades donde se verifica el uso de los recursos y donde se puede encontrar el origen de muchos de los problemas [...] La sustentabilidad [...] no es una actividad específica sino más bien un concepto que refiere una manera de visualizar, de enfocar y de orientar la solución de los problemas que se tienen con el entorno -ambiental, social, económico y político (Jiménez, 1998: 9).

Desde el punto de vista de sustentabilidad, lo anterior requiere como una condición necesaria, entre otras cosas, un balance que sea capaz de aprovechar las dinámicas producidas por el surgi- 
miento de nuevos actores y nuevos espacios de acción. Parafraseando a Boekema, podemos señalar que para que la política (turística, en este caso) sea eficiente, lo ideal sería la producción y el aprovechamiento de las posibles sinergias entre las acciones que provienen de arriba-abajo, las cuales se encargan de promover el desarrollo estructural; en concordancia con las acciones de $a b a-$ jo-arriba, las cuales surgen debido a la unicidad de cada localidad y territorio (Vázquez Barquero, 1986: 225).

Por ello, para una realidad como la que experimentan las comunidades a las que haremos referencia a continuación, es posible afirmar entonces, que el desarrollo sustentable debería ser un proceso de cambio social, dinámico, de carácter no lineal, el cual ocurre en un territorio definido por dimensiones económicas, ecológicas, sociales, culturales y políticas que se encuentran en constante interacción. ${ }^{8}$ Por ello, el origen y destino del cambio se halla en estas dimensiones -localizadas en el ámbito de las comunidades que se pretende impulsar-a través de la participación de los distintos actores, en y a lo largo de todo el proceso, teniendo como marco el uso sustentable de los recursos, tanto humanos y materiales, como de las características culturales y étnicas, con el objetivo de incidir en el mejoramiento de la calidad de vida de la población a la que se haga referencia. Tomando lo anterior como

\footnotetext{
${ }^{8}$ No es el objetivo de este trabajo discutir acerca de la 'primacía económico-ecológica' que se ha creado en torno a la sustentabilidad. Sin embargo, sí podemos señalar que en la mayor parte de los debates e investigaciones que tienen como objeto el desarrollo sustentable y el turismo se hace énfasis en los aspectos ecológicos. Así, se piensa en un desarrollo que es ecológicamente sostenible, el cual conserva el sistema natural en el que se desenvuelve el ser humano. No obstante, en muchas de las ocasiones, ello deviene en detrimento de las posibilidades de superar el hambre, la pobreza, y en última instancia, el desarrollo humano. De tal suerte, el desarrollo turístico sustentable se planea de un modo en el cual resulta posiblemente sostenible desde la perspectiva ecológica, pero inviable social, económica y políticamente. Ante esto, es necesario repensar la noción de sustentabilidad, en el sentido de que ésta se halla compuesta por otras dimensiones además de las ecológica (sociocultural, económica, político-institucional). De manera concreta observamos, en la relación de exclusividad establecida entre un grupo social delimitado con respecto a su patrimonio natural y cultural, uno los principales componentes de la dimensión sociocultural de la sustentabilidad. En este contexto, creemos necesario prever y analizar los impactos que pudieran incidir en esta dimensión, derivados de cualquier actividad que implique interacción entre actores. Con ello nos referimos al posible aumento en la fragmentación y reducción del campo social y cultural en el que se desenvuelven las comunidades indígenas. Para el caso que nos ocupa, lo anterior se derivaría de actividades tales como el turismo alternativo en los espacios de las comunidades indígenas nativas de в.c. Específicamente, hacemos énfasis en que el flujo turístico puede llegar a producir diversos impactos de carácter social y cultural en las localidades receptoras. Sabemos que en una localidad turística, la interacción ocurre en buena medida entre bagajes culturales totalmente distintos. Para una discusión al respecto (véase González, 2000).
} 
coordenadas conceptuales, procederemos a revisar el caso de las etnias indígenas nativas de Baja California.

\section{Las comunidades indígenas nativas de Baja California: su entorno}

Si bien es cierto que Baja California aparece en el contexto nacional como un estado que presenta indicadores de desarrollo social muy halagadores y en la que todos sus municipios tienen tasas de marginalidad muy bajas (CONAPO, 2000), vale la pena mencionar que existe un proceso muy alto de concentración-dispersión de la población, de la infraestructura y de los servicios en las cinco cabeceras municipales. En éstas se concentra $81 \%$ de la población estatal; el restante 19\% se dispersa en localidades menores a 2,500 habitantes, las cuales se encuentran desarticuladas social y económicamente del resto de la entidad (INEGI, 2001). Este es el caso de las comunidades estudiadas.

Tanto en México como en Baja California se ha pretendido integrar al indígena a la nación o a la entidad, según sea el caso, mediante la desaparición de sus elementos culturales, sin respeto por sus prácticas ancestrales y su cosmogonía, acaso conservándolos en un museo como recuerdo de un pasado lejano y olvidado. Hoy en día esta visión, que ha sido bastante cuestionada, debe dar origen a otra que enaltezca los valores y tradiciones de los indígenas. Por ello, coincidimos con Bonfil (1991: 72) cuando afirma que "[...] las culturas indias dejan de parecer prescindibles, marginales, o en definitiva, condenadas por la historia y pasan a ocupar un sitio crucial en tanto portadoras de un proyecto civilizatorio alternativo".

En términos generales, podemos decir que las culturas indias de México representan expresiones concretas de civilizaciones únicas. En buena medida, éstas se han enfrentado históricamente a un proceso de extinción territorial y étnico. Este fenómeno se presenta de manera palpable en las comunidades autóctonas de Baja California, los cuales han estado condenadas al olvido por parte de las políticas de desarrollo de los gobiernos estatal y federal.

De acuerdo con lo argumentado por Wilken (1998: 9), Piñera (1994) y el INI (1998), el territorio kumiai se extendía al norte hasta la altura de Escondido, en California, mientras que hacia el sur llegaba hasta Santo Tomás, en Baja California, atravesando gran parte de la Sierra Juárez. En la actualidad, dicho territorio se encuentra dividido por la frontera internacional entre México 
y Estados Unidos. De este modo, se localizan 15 reservaciones indígenas en el área de San Diego y cuatro comunidades indígenas en Baja California.

Las adaptaciones y diferencias culturales que dieron origen a los diversos grupos étnicos nativos del noroeste de B.C. ocurrieron durante el periodo prehistórico tardío. Con el descubrimiento de la agricultura, y el posterior procesamiento de la bellota, el complejo cultural y humano experimentó un cambio revolucionario en su adaptación al medio. De ello se derivaron grupos de menor magnitud y más estables, capaces de explotar los recursos naturales de manera intensa. Aunado a lo anterior, estos grupos se relacionaron cada vez más con otros sistemas económico-sociales como resultado del intercambio de artículos, tecnología y conocimientos. Esto tuvo como consecuencia una gradual separación lingüística y social de la población (Garduño, 1994:23).

Así, los grupos étnicos nativos que aún subsisten en la actualidad, se distribuyen en cinco núcleos con asentamiento en tres comunidades legalmente reconocidas, cuatro ejidos, cuatro posesiones de hecho y uno aún en lucha para que se le reconozcan sus tierras (Carvajal, 1998).

Las comunidades indígenas que habitan la parte noroeste de la península de Baja California enfrentan una problemática similar a la del resto de las etnias indígenas en todo el espacio nacional: situaciones de pobreza y pobreza extrema que conllevan a la insuficiencia alimentaria, de salud, educación y vivienda; territorios con un bajo potencial agropecuario y forestal, carencia de servicios públicos, entre otras (INI, 1998). Para el caso que nos ocupa, algunos estudios señalan que, de formar un contingente de entre 40 y 50 mil antes de la llegada de los españoles, en la actualidad sólo quedan en Baja California alrededor de mil indígenas, los cuales conforman cuatro grupos étnicos de origen $\mathrm{Yu}-$ mano: los Kumiai, los Paipai, los Cucapá y los Kiliwa (Garduño, 1994; Piñera, 1994). Actualmente, al clasificar a los grupos étnicos en relación con su lugar de procedencia, se encontró que para el año 2000 había 37,685 habitantes mayores de 5 años que hablan alguna lengua indígena en Baja California, de éstos solamente el 1.5\% eran originarios del estado, es decir, 560 personas (INEGI, 2000).

Dadas las condiciones de aridez de las tierras y los enormes recursos económicos que se requieren para hacerlas producir, la agricultura en ambas comunidades es de subsistencia. Aún así, ésta es la principal actividad económica a la que se dedican. Por 
tanto, no es suficiente para generar empleos para toda la población (Wilken, 1998; INI, 1998).

Por ello, los indígenas nativos de las comunidades estudiadas vislumbran al ecoturismo como una de las posibles para subsistir. Esto es así porque ambas comunidades están localizadas en una región cercana al puerto de Ensenada. Con base en el trabajo de campo realizado, puede decirse que las actividades turísticas se perciben, por parte de los indígenas, como una oportunidad de generar ingresos económicos y empleo para sus familias. Esto les permitiría vivir dignamente sin necesidad de recurrir a trabajos 'riesgosos' como el cultivo de narcóticos, que según integrantes de la comunidad, ocurre de manera clandestina en las áreas montañosas cercanas. Como se observa, el caso que analizamos no se refiere a una 'evaluación' a posteriori de la puesta en marcha de un proyecto de corte turístico en las mencionadas comunidades. Más bien, nos interesa analizar su gestación.

Ahora bien, la problemática de dichas comunidades se acentúa debido a su condición minoritaria, ya que éstas aun constituyen una minoría con respecto a la población indígena que habita en la entidad (INEGI, 2000). Bajo este escenario, enseguida se ofrece una breve introducción a la situación en la que se encuentran inmersas dichas comunidades, tratando de precisar las condiciones en las que se desarrollan y la necesidad que tienen de buscar alternativas que les permitan subsistir sanamente y sin necesidad de hipotecar su desarrollo. Dichas comunidades, a pesar de disponer de una relativa abundancia de recursos naturales y culturales, enfrentan, de manera paradójica, graves problemas económicos y sociales (INI, 1998).

Con el objeto de contextualizar la importancia de la situación antes descrita, asumimos que el posible entorno en el que las mencionadas comunidades podrían desempeñarse, en virtud de la posibilidad de convertirse en actores del proceso turístico en Baja California, tiene como referente la región conocida como Valle de Guadalupe, espacio en el que se circunscriben ambas etnias, a pesar de la resistencia por parte de las autoridades locales y los propios vitivinicultores de incorporarlas como parte de esta próspera región.

El Valle de Guadalupe es la zona en la que confluyen la historia de las dos comunidades indígenas de Baja California, la historia misional y la herencia cultural de la comunidad rusa, la cual ha sido fundamental para otorgar a la zona su sello característico, (Piñera, 1994). El clima, las particularidades del suelo y las 
condiciones hidrológicas han favorecido el desarrollo de la industria del vino, hasta hoy uno de los símbolos que identifican la vocación económica de esta región (García et al., 1995; Villa, 2002).

En este sentido, el Valle de Guadalupe es conocido internacionalmente por la calidad de sus vinos: en él se genera 95\% de la producción de vinos de mesa en México. Los grandes productores ubicados en este Valle son las compañías L.A. Cetto, Vides de Guadalupe Domecq; el resto, son pequeños productores de vinos de excelente calidad y altamente competitivos en el ámbito internacional. Estos productores son Monte Xanic, Chateau Camou, Mogor-Badán, Viña Liceaga, Casa de Piedra, y Bodegas Valle de Guadalupe (Sánchez, 2000; Villa, 2002).

Aunado a lo anterior -y pese al poco equipamiento turístico y recreativo que existe en esta zona- es posible pensar que las comunidades indígenas a las que nos referimos pueden ser vistas como una opción viable para diversificar la oferta de actividades turísticas hacia la región; aprovechando los flujos de visitantes que llegan en crucero a Ensenada y que muchas veces no quieren descender a tierra pues -según el administrador del puerto- los turistas han expresado su inconformidad en cuanto a que no existen suficientes atractivos para visitar, ni actividades para realizar en la ciudad (entrevista con Carlos Jáuregui, administrador del Puerto de Ensenada).

Semanalmente arriban al puerto de Ensenada tres cruceros turísticos, de ellos desembarcan mensualmente 25,445 turistas; tan sólo en 2002 llegaron un total de 305,338 turistas por vía marítima (SECTURe, 2003). Dado que este mercado está cobrando importancia a raíz del proyecto escalera náutica, el administrador del puerto ha manifestado su interés por llevar el turismo hacia el Valle de Guadalupe, de tal manera que se pueda diversificar la oferta y hacer más atractiva la llegada de cruceros al puerto, logrando así incrementar la estancia de los visitantes (entrevista con Carlos Jáuregui, administrador del Puerto de Ensenada). De hecho, en la actualidad algunas compañías particulares de transporte turístico empiezan a incorporar de manera incipiente algunos tours hacia esta zona.

En este sentido, se puede aprovechar el potencial cultural y natural existente para conformar un producto turístico único que incorpore no sólo la región vitivinícola del Valle de Guadalupe, sino también a las comunidades indígenas adyacentes, con la finalidad de atraer nuevos segmentos del mercado que están en 
proceso de gestación en la zona: el 'turismo rural' y el ecoturismo, mientras que ambos forman parte de lo que se denomina turismo alternativo (véase González, 2000).

De hecho hoy en día la zona de San Antonio de las Minas, un pequeño poblado que forma parte del Valle de Guadalupe, es conocida por sus restaurantes rústicos situados a lo largo de la carretera, donde el ya típico 'pastel de manzana' ruso le ha otorgado un sello de identidad a la zona, al igual que los platillos rusos que se ofrecen en el museo comunitario. Dicha tradición culinaria fue introducida a la región por los colonos rusos molokanes que llegaron a la entidad a inicios del siglo xx y que conformaron una colonia agrícola (entrevista con Francisca Samarin, directora del Museo Comunitario Ruso). Además de la comida, tanto las grandes casas productoras (Cetto y Domecq) como las pequeñas brindan servicio de degustación y visita a los viñedos. De la misma manera en las viviendas de algunos habitantes se vende vino casero y algunos productos regionales como mermeladas, pan ruso, hierbas medicinales, semillas orgánicas, entre otros.

Sin duda, el Valle de Guadalupe puede posicionarse como un nuevo destino turístico y aprovechar las ventajas comparativas de estar incluido en un sistema regional más amplio, caracterizado por contar con una demanda turística consolidada. Dicho sistema se conoce como Corredor Costero Tijuana-Rosarito-Ensenada (Cocotren) que es la región donde confluye la mayor parte de las divisas turísticas que ingresan a la entidad. Tan sólo en 1996, el gasto anual generado en esta región ascendió a 425 millones de dólares (Colef-CEsTur, 1997).

Asimismo esta región cuenta con una oferta hotelera diversificada al ofrecer 117 hoteles de distintas categorías, 40 fraccionamientos de lujo en forma de segundas residencias para extranjeros, 64 trailer parks para un turismo de menores ingresos y 16 espacios para acampar. Creemos que, en buena parte, la conformación de un producto turístico alternativo permitiría diversificar y complementar la oferta turística tradicional, ya que se ofrece en la entidad en general y en el Cocotren en particular. Con ello se satisfarían las necesidades de una demanda potencial que busca realizar otras actividades durante su estancia, tanto en el puerto de Ensenada como en otras localidades del corredor (Bringas, 2002).

En la entidad existen comunidades indígenas como Santa Catarina y el Mayor de Cucapá que también cuentan con recursos naturales y culturales que les permitirían promover su potencial 
ecoturístico y a partir de él propiciar un desarrollo local; no obstante para efectos de este trabajo el análisis se centra en dos comunidades: San José de la Zorra y San Antonio Nécua, ambas pertenecientes a la rama étnica kumiai. La idea de estudiar estas comunidades, como ha sido mencionado anteriormente, nació del interés expreso de sus miembros por explorar la posibilidad de desarrollar el ecoturismo, dados los recursos naturales y culturales con los que cuentan, tratando con ello de buscar alternativas de desarrollo a su precaria situación económica. En ambas comunidades es posible desarrollar actividades ecoturísticas tales como: paseos a caballo por los alrededores del poblado, caminatas, ciclismo de montaña, actividades pedestres, juegos al aire libre, visita a las pinturas rupestres, a la cascada y a las aguas sulfurosas, observación de aves y actividades cinegéticas controladas.

Sabemos que el contar con recursos naturales y culturales no es suficiente para garantizar la conformación de un producto turístico, pues finalmente es la valoración social la que le garantiza su atracción como tal. No obstante, creemos que existen elementos que nos indican que estas comunidades integradas al Valle de Guadalupe pueden convertirse en un producto turístico diferente a los tradicionales destinos de sol y playa existentes, siempre y cuando los actores locales participen con iniciativas de proyectos productivos potenciales relacionados con actividades turísticas de bajo impacto.

Antes de describir el potencial que ambas comunidades tienen para desarrollar el ecoturismo, es pertinente aclarar el método y las técnicas utilizadas para obtener la información. Nuestra primera visita a la zona fue en el año 2000, a invitación de uno de los miembros de la mesa directiva de San José de la Zorra, donde participaban todas las etnias nativas de la entidad para discutir la problemática de la tenencia de la tierra. En esta asamblea comunitaria, se nos solicitó apoyo para que les ayudásemos a deslindar los límites del territorio ocupado por esa comunidad. Los miembros de esta comunidad querían hacer una propuesta al gobierno para que se les reconocieran sus derechos como comunidad indígena, dado que con la Reforma Agraria pasaron a formar parte del Ejido Porvenir (entrevista con Gregorio Montes, miembro de la Mesa Directiva).

Al finalizar la asamblea, se acercaron los representantes de ambas comunidades y nos expusieron su deseo de que los apoyáramos a hacer un estudio para obtener fondos del INI de México para hacer un proyecto ecoturístico que les permitiera construir 
cabañas para alojar a los visitantes que de manera incipiente acuden a la zona, dado que no hay establecimientos de hospedaje. Los viajeros que llegan normalmente traen sus tiendas de campaña y acampan bajo los encinales o cerca del represo que los nativos de San José construyeron pensando en colocar ahí las cabañas donde alojarán a los visitantes. El sitio escogido por ellos está alejado de lo que es el centro de la comunidad, porque querían que los visitantes no afectaran su vida cotidiana. Lo mismo sucedió en San Antonio Nécua, pues el lugar seleccionado por ellos estaba a la entrada del poblado bajo un enorme encinal.

A partir de entonces, nuestras visitas a ambas comunidades se hicieron periódicas (fines de semana y vacaciones). Para hacer parte del trabajo de campo, la comunidad entera apoyó, unos prestaron sus caballos, otros su fuerza de trabajo, algunos miembros de la comunidad fungieron como guías para detectar las mojoneras y las mujeres cocinaron los alimentos que se iban a llevar durante el trayecto en el que se recorrió un perímetro de aproximadamente 53 kilómetros a lomo de caballo, alrededor de un área de $190.3 \mathrm{~km}^{2}$. Junto con algunos miembros de la comunidad, se hizo el levantamiento físico de la información para delimitar los linderos, se identificaron las mojoneras originales y con un posicionador satelital (GPS) se obtuvieron las coordenadas tanto de los límites como de los sitios naturales e históricos susceptibles de aprovecharse con fines ecoturísticos.

Asimismo se hicieron entrevistas con actores clave para obtener la información necesaria que nos diera elementos para verificar si había consenso de desarrollar el ecoturismo. En reuniones de asamblea, les explicamos los riesgos que esa actividad traería consigo si era mal manejada y la necesidad de involucrar exclusivamente a gente local. Nos sorprendió la claridad con la que manifestaron que necesitan emplearse (pues en caso contrario surgía la necesidad de emigrar) y que ellos preferían quedarse en sus tierras porque se sentían orgullosos de su historia y sabían de las ventajas que podría traer el ecoturismo pues algunos miembros de la comunidad iban a las reservas indias del 'otro lado' a vender sus artesanías, y saben que los extranjeros están dispuestos a pagar por lo que valen, pues hacerlas les toma bastante tiempo.

Martín, uno de los miembros de la comunidad, comentó que querían hacer del ecoturismo una actividad buena, no como el narcotráfico que acababa con las familias. De hecho el ejemplo que dio para definir lo querían fue contundente: "creemos que no debemos traer mucho turismo pues acabaría con la comuni- 
dad, es como con las semillas, si las siembras todas y hay una sequía, no te queda nada para el año siguiente, y ¿qué le vas a dar de comer a tus hijos?”

\subsection{San José de la Zorra (Mexna'n: nido de ratas)}

La comunidad indígena kumiai de San José de la Zorra se encuentra situada en los límites municipales de Ensenada y Playas de Rosarito, en el estado de Baja California (véase mapa). Específicamente, el lugar se encuentra localizado en las intermediaciones de los poblados de La Misión y el ejido El Porvenir; el acceso se encuentra aproximadamente a 38 kilómetros de la carretera Tecate-Ensenada por el Valle de Guadalupe, y a partir de aquí deben recorrerse 16 kilómetros de terracería.

Una vez que se llega al pueblo formado por 114 personas, se observan diseminadas decenas de casas que conforman el paisaje urbano del poblado junto con el templo, la 'tiendita' y las celdas solares que hacen funcionar el teléfono rural. Con respecto a las 24 viviendas localizadas en esta comunidad, se observa que la mayor parte de ellas se encuentra hecha de material tipo adobe y ladrillo. También es posible encontrar en las construcciones materiales como lámina y madera (INEGI, 2000, verificación de campo).

Es pertinente destacar que la distancia que separa cada una de las viviendas es de aproximadamente un kilómetro. De ello se deriva que el núcleo poblacional sea poco detectable a simple vista. Este hecho ha dificultado en gran medida la dotación de servicios públicos como el agua y la electricidad a la comunidad, ya que dicha separación implica dificultades técnicas que elevan enormemente los costos de introducción. Eso explica que solamente una vivienda cuenta con agua entubada proveniente de un pozo y sólo una cuenta con drenaje conectado a fosa séptica. Ninguna vivienda cuenta con energía eléctrica (INEGI, 2000).

En varias visitas de campo fue posible constatar que la producción de artesanías hechas de sauce y junco es una de las principales actividades económicas que se desarrollan en la comunidad; a ello se suman la ganadería y la agricultura limitada. En menor escala se realizan actividades relacionadas con la recolección y comercialización de miel y semillas silvestres. ${ }^{9}$

En este contexto, se puede decir que tanto las asambleas comunitarias a las que se asistió como las entrevistas que se lleva-

${ }^{9} \mathrm{Al}$ respecto, Wilken, (1998:18) señala que las semillas recolectadas se utilizan para el control de la erosión en California y en algunas regiones mediterráneas de Europa. 


\section{Mapa de localización del área de estudio}

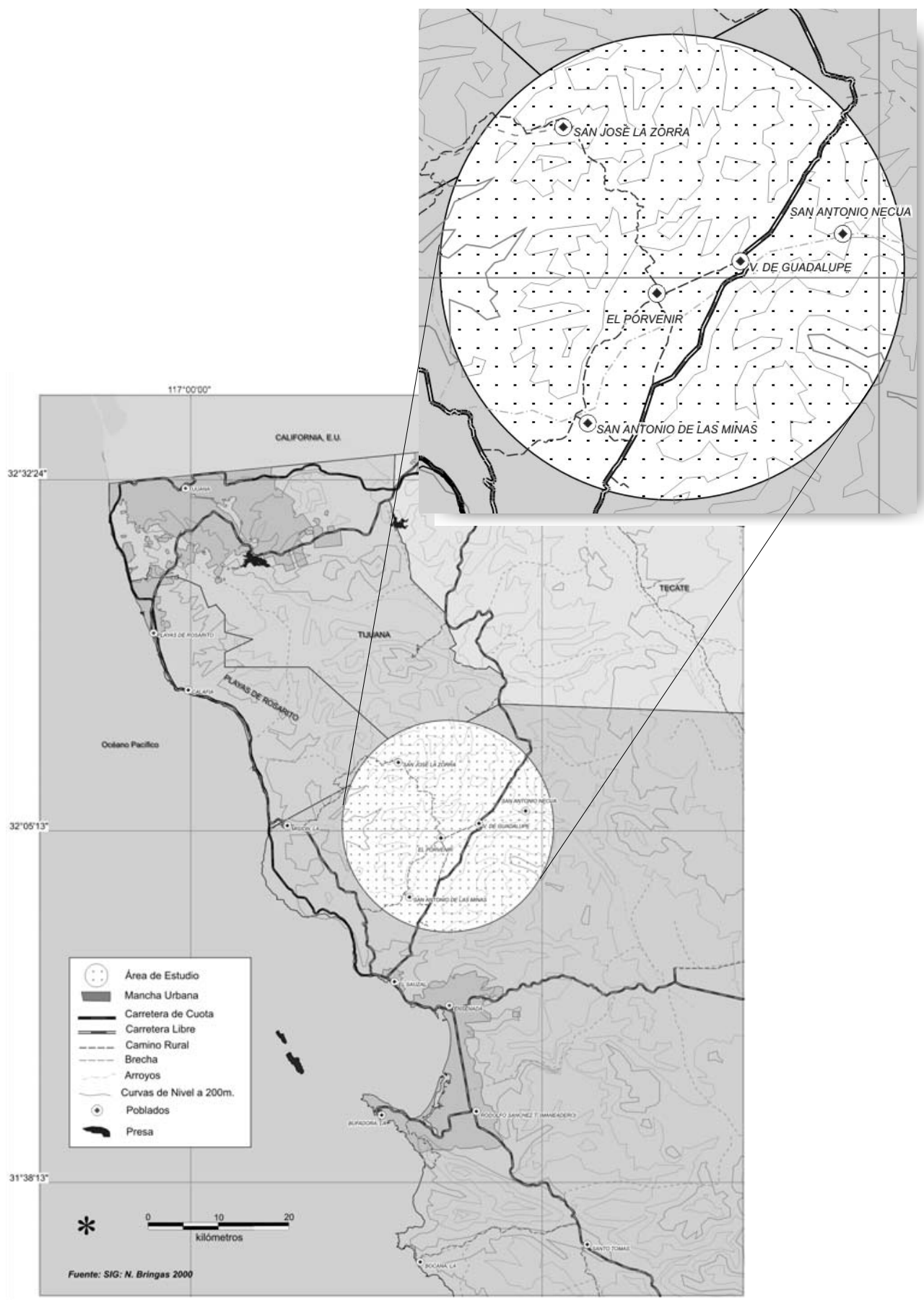


ron a cabo con distintos personajes al interior de la comunidad nos permiten señalar que los indígenas de San José de la Zorra perciben las actividades turísticas como una buena opción tanto para generar empleos en la localidad, como para la comercialización de las artesanías que éstos producen. De hecho, Doña Gloria, la autoridad tradicional de San José de la Zorra, y una de las figuras más respetadas de la comunidad comenta “[...] a veces, muchas de las veces, vienen algunos turistas que compran una o dos piezas. Es importante para nosotros que esa artesanía salga".

Cabe destacar que la comercialización de las artesanías elaboradas en San José de la Zorra han traspasado los límites de la frontera geopolítica, pues la más de las veces son vendidas en las reservas indias del vecino estado de California, o en ferias y exposiciones también del 'otro lado', donde se paga en dólares y a un precio más elevado por ellas. Sin embargo, este hecho no ha posibilitado que esta comunidad supere el desempleo y las condiciones de pobreza en las que viven, pues según ellos mismos, elaborar estas vasijas lleva mucho tiempo y necesitan hacer otra actividad para sobrevivir, lo que ha dificultado que más familias le dediquen tiempo a la elaboración de artesanías. ${ }^{10}$ De instrumentarse un proyecto ecoturístico, las mujeres de la comunidad piensan poner una cooperativa para poder comercializar las artesanías que producen.

En tales circunstancias, el turismo representa para la comunidad una forma de explorar alternativas productivas a través del apoyo del gobierno (FONAES) y de algunas organizaciones no gubernamentales, con la idea de que mediante sus propios medios y con los recursos obtenidos puedan desarrollar opciones fecundas y hacer frente a las problemáticas que ya hemos referido. Sin duda, los miembros de esta comunidad se reconocen como poseedores de un enorme potencial desde el punto de vista de los recursos naturales y culturales; pero también reconocen sus carencias, sobre todo en relación con la participación y la organiza-

${ }^{10}$ El hecho de que estos indígenas hayan logrado vender sus artesanías a mejores precios en 'el otro lado', no garantiza que puedan hacer lo mismo en México; de hecho los altos costos de las mismas ha dificultado su venta en 'este lado', pues las artesanías se comercializan solamente en algunas tiendas del primer cuadro de la zona turística de la ciudad de Ensenada, y dadas las características del mercado tradicional de visitantes, que normalmente buscan precios bajos, su venta no es muy frecuente. Por ejemplo, un adorno de junco circular de $30 \mathrm{~cm}$. de diámetro lo venden en 500 pesos o su equivalente a 50 dólares en Estados Unidos, pero ese precio parece caro en un contexto mexicano, donde el mercado chino ha introducido copias similares a precios mucho más baratos, lo que sin duda va en detrimento de la comercialización de productos auténticos y de gran valor cultural. 
ción de la comunidad. Al respecto, uno de los integrantes de la mesa directiva señalaba que "muchas de las veces se cree que con firmar el acta de la asamblea se está participando. Y no es así, se requiere que la comunidad se involucre más [...]" (entrevista con Gregorio Montes).

\subsection{San Antonio Nécua (Jneau scuix: la curva de los encinos)}

La comunidad indígena kumiai de San Antonio Nécua se encuentra ubicada en la delegación Francisco Zarco, en el municipio de Ensenada, Baja California. El lugar se localiza a la altura del kilómetro 38 de la carretera Ensenada-Tecate. De hecho, el actual asentamiento se sitúa al margen del río Guadalupe, cercano a los campos vitivinícolas de las casas productoras de vino Cetto y Domecq.

En los resultados obtenidos por INEGI para el año 2000, se señala que este poblado contaba con 119 personas solamente. En ese mismo año existían 21 viviendas ocupadas en la comunidad. En relación con las condiciones de la vivienda en esta comunidad, se observa que la mayoría de las construcciones son de ladrillo y adobe; también materiales como la madera y la lámina se encuentran presentes. El núcleo poblacional es fácilmente distinguible, a diferencia de la comunidad de San José de la Zorra. Para San Antonio Nécua se observa que casi la totalidad viviendas cuentan con energía eléctrica y drenaje.

Por lo que toca a las actividades económicas del poblado se encontró que se desarrolla principalmente la agricultura y la ganadería (entrevista con Andrés Ceseña, comisario ejidal de San Antonio Nécua). Con la agricultura de riego se cultiva alfalfa. Aunado a ello se practica la ganadería extensiva y en menor medida la extracción de material de construcción y la fabricación de ladrillos de adobe. También se encontró que algunos de los pobladores de la comunidad trabajan como asalariados en los ranchos vitivinícolas y en otras industrias situadas en las inmediaciones del poblado (INI, 1998; Wilken, 1998, verificación de campo).

Al igual que en San José de la Zorra, en esta comunidad se percibe al turismo como una oportunidad para el desarrollo. Los elementos culturales y naturales que poseen les han permitido vislumbrar el potencial que tienen en relación con las actividades turísticas. De hecho, el comisario ejidal de esta comunidad comentó que "[...] hay un grupo de mujeres que están muy interesadas en el proyecto [...] Como ve, nosotros estamos en la mejor 
disposición. Sólo nos falta el recurso (monetario)". Cabe destacar que el turismo no representa 'la salvación' de la comunidad, sino una forma de diversificar sus actividades productivas, de hecho, que se tienen identificadas las áreas donde es factible ubicar equipamiento de tipo turístico-recreativo como cabañas, áreas para acampar, asadores y juegos, entre otros (entrevista con Andrés Ceseña, comisario ejidal de San Antonio Nécua).

En los párrafos anteriores hemos tratado de describir de manera breve la situación actual en la que se desenvuelven estas dos comunidades nativas de Baja California. Con base en ello, creemos que es necesario repensar la noción de sustentabilidad ya que ésta se halla permeada de origen por un afán 'naturalista'; con ello se pretende complementar y trascender la primacía ecológico-económica que se ha construido alrededor de dicha noción.

\section{Comentarios finales: algunos elementos para la estructuración de políticas turísticas de corte alternativo}

Es pertinente hacer notar que si bien los cambios que experimenta la actividad turística obedecen a lógicas de orden mundial, éstos tienen sus expresiones concretas en el ámbito de lo local. Para el caso que nos ocupa, tanto el surgimiento de nuevos actores, como la tendencia hacia la consolidación de los ya existentes, permiten observar una recomposición del escenario de lo turístico en Baja California, el cual apunta hacia la diversificación del producto turístico.

Uno de los factores que explican esta recomposición deriva, en buena medida, de las demandas expresadas por las dos comunidades indígenas aquí analizadas. Con base en el potencial turístico de sus recursos naturales y culturales, en dichas comunidades se ha mostrado el interés de explorar alternativas productivas relacionadas con el turismo. Desde nuestro punto de vista, resultaría erróneo considerar a estas comunidades como aisladas de la propia actividad turística. La existencia de actores reales de lo turístico en las zonas aledañas, como es el caso del Museo Comunitario del Valle de Guadalupe (conocido como El Museo Ruso), así como de algunos actores interesados en participar, de entre los que destaca el Instituto de Culturas Nativas de Baja California (Cuna) y la propia Delegación Regional del INI, así como la dinámica que se genera a partir del desempeño de éstos, crea oportunidades para que las comunidades pudieran aprovechar su potencial turístico. 
En este contexto, es destacable el papel del Museo Ruso, ${ }^{11}$ en tanto agente capaz de dinamizar el proceso turístico, así como de articular en cierto grado las demandas de las comunidades en relación con los otros actores. Al aprovechar tanto los recursos como promover el potencial que existe en la zona, el museo paulatinamente se encuentra construyendo su propio nicho de mercado. Cabe señalar que las dinámicas que se generan a partir de lo anterior merecen ser analizadas y sistematizadas, con el fin de contribuir al mejor conocimiento acerca del desempeño de uno de los actores que se perfila como el principal motor de lo que podría denominarse como el contexto del turismo alternativo del Valle de Guadalupe (Bringas, Cuamea y González, 2000).

Sin embargo, es preciso reconocer que ello no es suficiente. La exploración de alternativas productivas de corte turístico tiene como condición necesaria la existencia de cierto potencial desde el punto de vista de recursos culturales y naturales. Sobre todo si el objetivo consiste en lograr detonar el proceso de desarrollo para las comunidades bajo estudio. Para que esto resulte es necesario, además, tomar en consideración aspectos tales como las capacidades de organización y gestión al interior de cada comunidad, así como las formas y grados de participación y vinculación existentes tanto internamente como con los distintos actores que se desenvuelven en el escenario turístico de la zona y de la entidad.

Pero, sobre todo, es necesario que las actividades turísticas sean percibidas por parte de la comunidad como una verdadera oportunidad para el desarrollo. Si se pretende poner en marcha un proyecto de corte turístico sin contar con el consenso comunitario y sin objetivos claros y previamente establecidos, se corre el riesgo de que dicho proyecto, más que una oportunidad, represente un obstáculo, teniendo como desenlace una serie de consecuencias que bien pueden resultar altamente negativas.

Por otra parte, cabe mencionar que uno de los impactos nocivos que el turismo genera es que ha permitido el estado de atraso de algunas regiones para atraer visitantes; es decir, muchos de los países en vías de desarrollo comprometen su 'desarrollo', precisamente en la comercialización de su subdesarrollo; de esta ma-

${ }^{11}$ El Museo Comunitario Ruso actualmente funge como promotor de las comunidades y los atractivos existentes en la región, ya que a partir de éste se hacen recorridos turísticos guiados a las pequeñas casas productoras de vino, las pinturas rupestres y a los restaurantes existentes en la zona, además de que el propio museo ofrece en sus instalaciones rústicas comida rusa. En este museo también se comercializa parte de las artesanías que producen las comunidades indígenas (entrevista con Francisca Samarin, directora del Museo Comunitario Ruso). 
nera estos países resultan exóticos o folklóricos a los ojos de quienes los visitan, acentuando con ello aún más las desigualdades existentes (Lee, 1978). Esta situación que ha prevalecido en algunos países puede ser igualmente perniciosa para las comunidades indígenas y el riesgo de que esto suceda no es remoto: todo dependerá de quiénes y cómo promuevan el ecoturismo, aunque los líderes de estas comunidades aseguran que no quieren 'mucho turismo', sólo quieren trabajo e ingresos para sus familias.

Si bien es cierto que el turismo provoca efectos benéficos en la estructura económica al generar empleos y divisas, y al producir encadenamientos productivos y efectos multiplicadores en otras actividades, también es cierto que sus efectos positivos pueden llegar a desplazar a las actividades productivas tradicionales y generar con ello una monodependencia, lo cual es muy riesgoso dado lo estacional de la actividad. Sin duda el turismo contribuirá a transformar las prácticas sociales y las pautas de comportamiento de las comunidades receptoras, pero ante un mundo globalizado no podemos adjudicar que sólo el turismo sea el culpable de todos esos cambios. Cabe señalar que los costos del turismo pueden llegar a superar los beneficios generados, pero ese es un reto al que deberán enfrentase las comunidades, ya que es igual de peligroso continuar sin alternativas de sobrevivencia.

Considerando la fragilidad de los espacios en los que se pretende promover el ecoturismo, éste se presenta como un arma de dos filos. Por un lado, si es llevado a cabo en forma adecuada, puede conducir a un proceso de desarrollo inscrito dentro del marco de la sustentabilidad, e incluso, guiar por este sendero a gran parte de las prácticas turísticas. Por otro lado, si se realiza sin un cuidado y controles pertinentes, los costos sociales, culturales y ambientales que éste genera pueden superar en gran medida a los beneficios económicos.

Se ha dicho ya que sobre la base de las intenciones expresadas por las propias comunidades, así como de los estudios antes mencionados, se plantea al ecoturismo como una manera innovadora de explorar alternativas de desarrollo, aunque no se debe soslayar el carácter dual que esta actividad representa. Tomando en consideración lo argumentado en párrafos anteriores, podemos señalar que los resultados de este primer acercamiento al tema y a ambas comunidades indican que en el caso de San José de la Zorra se presenta relativamente un mayor potencial en términos turísticos (González, 2000). Sin embargo, también se observa que adolece en mayor medida de capacidades de organización y ges- 
tión. Aunado a lo anterior, las carencias en materia de infraestructura y servicios básicos de esta comunidad representan un obstáculo para la exploración de alternativas productivas relacionadas con el turismo. El aspecto relacionado con la infraestructura y los servicios básicos podrían tener solución mediante la intervención gubernamental en el corto plazo, mientras que el que se refiere al fomento a las capacidades de organización y gestión requiere de programas y asesoría que arrojarían resultados hasta el mediano y largo plazos.

Además, en la mencionada comunidad, el interés de explorar proyectos productivos relacionados con el turismo no se ha cristalizado totalmente. Se observa poca claridad en relación con los objetivos que se pretenden alcanzar a raíz de la puesta en marcha de este tipo de proyectos. Lo anterior indica que se requiere de mayores esfuerzos encaminados a clarificar y concretar la idea, así como de cubrir condiciones mínimas de infraestructura y servicios, tales como la energía eléctrica y la introducción de una red hidráulica, entre otras cosas. Ello con el objeto tanto de incrementar el nivel de vida de la comunidad como de contar con el equipamiento básico para facilitar el proceso turístico.

En suma, para San José de la Zorra, es preciso fomentar una clara visión de la dirección hacia donde se quiere llegar en tanto colectividad territorial que pretende explorar alternativas productivas basadas en las nuevas formas que adopta el proceso turístico. Para ello se requiere identificar y delimitar claramente tanto los roles como las responsabilidades que corresponde realizar a cada uno de los actores que intervendrían en dicha actividad, así como los vínculos reales y potenciales de éstos para con los otros actores del entorno.

Para la comunidad de San Antonio Nécua también se observa un alto potencial turístico, aunque éste es ligeramente menor al de San José de la Zorra. Sin embargo, en lo que se refiere a las capacidades de organización, gestión y negociación, observamos que éstas se encuentran mejor articuladas y desarrolladas en dicha comunidad. Ello subsana en buena medida la pequeña diferencia entre los potenciales que se observan para cada comunidad. Aunado a lo anterior, se tiene el hecho de que en ésta se cuenta con una cobertura casi total de los servicios básicos, así como de infraestructura y equipamiento capaces de recibir el flujo turístico en el corto plazo.

Ahora bien, para la mencionada comunidad es posible observar una mayor claridad con respecto a lo que se pretende obtener 
a partir de la exploración de las nuevas formas del turismo, en tanto alternativa productiva. De hecho, se han señalado áreas específicas destinadas a la construcción de infraestructura y equipamiento turístico. Aunado a ello se ha definido el tipo de infraestructura y equipamiento que se requiere para aprovechar su potencial turístico. También, se han identificado los grupos que, en la comunidad, estarían a cargo de la instrumentación y puesta en marcha de un proyecto relacionado con dicha actividad. En este contexto, además de apoyos en infraestructura y equipamiento, las acciones deberían estar encaminadas hacia la capacitación y asesoría técnica en materia de prestación de servicios necesarias para llevar a cabo los proyectos productivos de corte turístico.

En el contexto del Valle de Guadalupe, consideramos que San Antonio Nécua es la que presenta mayores posibilidades de explorar exitosamente proyectos productivos relacionados con la actividad turística en el corto plazo, aclarando que eso no excluye en ningún modo a la comunidad de San José de la Zorra. Sin embargo, creemos adecuado que sean cubiertas algunas condiciones mínimas de bienestar y que se fomenten y potencien las capacidades de organización y gestión en ésta última, previo a la puesta en marcha de cualquier alternativa productiva relacionada con la actividad turística.

De lo anterior se desprende que la estructuración de una política turística que involucre a las comunidades estudiadas debería contemplar, entre otros componentes, las siguientes líneas de acción: i) capacitación/sensibilización; ii) fomento a la creación y

\section{Cuadro 1}

Algunos de los componentes de una política turística regional

\begin{tabular}{|l|l|l|}
\hline \multicolumn{1}{|c|}{ Líneas de acción } & \multicolumn{1}{|c|}{ Descripción } & Actor \\
\hline $\begin{array}{l}\text { Capacitación/ } \\
\text { sensibilización }\end{array}$ & $\begin{array}{l}\text { Por una parte, la capacitación se dirigiría } \\
\text { hacia aspectos tales como la prestación de } \\
\text { servicios, cuestiones contables y } \\
\text { administrativas, entre otras. } \\
\text { Por otra parte, la sensibilización estaría } \\
\text { enfocada a senalar cuáles serían los costos y } \\
\text { los beneficios del turismo, así como a } \\
\text { cristalizar un proyecto turístico. }\end{array}$ & - SECTURE \\
\hline $\begin{array}{l}\text { Equipamiento e } \\
\text { infraestructura }\end{array}$ & $\begin{array}{l}\text { Se contempla aquí tanto la creación de nueva } \\
\text { infraestructura y equipamiento como el } \\
\text { acondicionamiento de los ya existentes. }\end{array}$ & $\bullet$ Populares \\
\hline Promoción & $\begin{array}{l}\text { SECTURE } \\
\text { INI/FONAES } \\
\text { SEDESOL } \\
\text { SEDECO }\end{array}$ \\
\hline
\end{tabular}

Fuente: Elaboración propia. 
habilitación de infraestructura y equipamiento; y, iii) promoción de un producto turístico alternativo (véase el cuadro 1).

De lo anterior se desprende que, para dar respuesta a las demandas de las comunidades aquí estudiadas, se requiere de mecanismos y acciones por parte no sólo de las instancias relacionadas con la actividad turística, sino también de aquellas que atienden la problemática de las etnias indígenas de Baja California. Lo anterior obliga a la construcción de espacios en donde sea posible la convergencia, la coordinación y el consenso de los distintos actores con capacidad y posibilidad de incidir en el proceso turístico. Desde nuestra perspectiva, tales espacios deberían construirse en el ámbito municipal, ya que en última instancia es ahí donde el turismo -tanto el modelo convencional como el alternativo- toma formas concretas.

\section{Bibliografía}

Aguirre Muñoz, Alfonso (1998), Desarrollo sustentable y mundo de la vida, Tesis doctoral, Colegio de la Frontera Norte, Tijuana, в.c., México.

Ayres, Robert U., Van der Bergh, Jeroen y Gowdy, John M. (s. f.) Viewpoint: Weak vs. Strong Sustainability, en <http:// www.ima.kth.se/Im/3c4385/pdf/ssws.pdf >, consultado el 21 de octubre de 2003.

Azevedo, Irving (1999), “Conceitos, metodología e liçoes aprendidas em projectos de desenvolvimiento: o contexto brasileiro", en Román Rodríguez González, Alcides Dos Santos Caldas y José Mascarenhas Bisnieto (coords.), Desarrollo local y regional en Iberoamérica. Actas del Seminario Internacional sobre Perspectivas de Desarrollo en Iberoamérica, Universidad de Santiago de Compostela, España.

Bonfil Batalla, Guillermo (1991), Pensar nuestra cultura, Alianza, México.

Bringas R. Nora L., Felipe Cuamea y J. Igor Israel González (2000), Programa de Desarrollo del producto turístico recreativo para las zonas rurales del estado de Baja California, Reporte de Investigación, Secretaría de Turismo del estado de Baja California, B.c. 
Bringas R., Nora L. (2002), "Baja California and California's merging tourist corridors: The Influence of Mexican Government Policies" in Journal of Environment \& Development, Journal of The University of California, San Diego, EUA, vol. 11, núm. 3, septiembre, pp. 267-296.

Bringas R., Nora L. y Lina Ojeda R. (2000), “El ecoturismo: ¿Una nueva modalidad del turismo de masas?" en Revista Economía, Sociedad y Territorio. El Colegio Mexiquense, A.C., Zinacantepec, México, vol. II, núm. 7, enero-junio, pp. 373-403.

Butler, Richard (1998), "Sustainable tourism-looking backwards in order to progress?", en C. Michael Hall \& Alan A. Lew, Sustainable Tourism. A geographical perspective, Prentice Hall, London, pp. 25-34.

Callizo Soneiro, Javier (1991), Aproximación a la geografía del turismo, Espacios y Sociedades 21, Editorial Síntesis, Madrid, España.

Carvajal, Norma (1998), Diagnóstico general de los grupos indígenas en Baja California, Instituto Nacional Indigenista, México.

Ceballos Lascuráin, Héctor (1998), Ecoturismo, naturaleza y desarrollo sostenible, Editorial Diana, México.

Colef-CESTUR (1997), El turismo en el corredor Tijuana-Ensenada, Reporte de Investigación, El Colegio de la Frontera Norte, Tijuana, B.c.

CONAPO (2000), Marginación municipal, en <http:// www.conapo.gob.mx/municipios/ principal.html>, $21 \mathrm{de}$ octubre de 2003.

Ferrás Sexto, Carlos y Xoan M. Paredes (1999), "Reflexiones sobre justicia social y desarrollo alternativo en América Latina”, en Román 
Rodríguez González, Alcides Dos Santos Caldas y José Mascarenhas Bisnieto (coords.), Desarrollo local y regional en Iberoamérica.

Actas del Seminario Internacional sobre Perspectivas de Desarrollo en Iberoamérica, Universidad de Santiago de Compostela, España.

García Hinojosa, César Alejandro; Ileana Espejel y Claudia Leyva (1995), Vocación de uso del suelo en el corredor vitivinícola: "San Antonio de las Minas-Valle de Guadalupe", Reporte de Investigación, Ensenada Baja California, B.C. (falta casa editora)

Garduño, Everardo (1994), En donde se mete el sol... Historia y situación actual de los indígenas montañeses de Baja California, CONACULTA, México.

González A., J. Igor (2000), El turismo alternativo como una vía para el desarrollo sustentable de las comunidades indígenas nativas de B. C.: San José de la Zorra y San Antonio Nécua, Tesis de maestría en Desarrollo Regional, El Colegio de la Frontera Norte, Tijuana, México.

Gunawardena, UADP (2002), The Fallacy of Weak Sustainability: The Case of Home Garden Bio Diversity of Sri Lanka, en $<\mathrm{http}: / / \mathrm{www} .202 .184 .25 .3 / \mathrm{conf}$ a a $2002 /$ program\&abstract/Gunawardena.pdf >, 21 de octubre de 2003.

Hediger, Werner (s.f.) “Reconciling 'weak' and 'strong' sustainability”, en International Journal of Social Economics, vol. 26, núm. 7/8/9, МСв University Press. (Faltan páginas)

INEgI (2000), XII Censo General de Población y Vivienda. Perfil sociodemográfico de Baja California, Instituto Nacional de Estadística, Geografía e Informática, México.

INEGI (2001), Anuario estadístico del estado de Baja California, Instituto Nacional de Estadística, Geografía e Informática, México. 
INI (1998), Diagnóstico general de características y principales problemas de las comunidades nativas de Baja California, Instituto Nacional Indigenista, México.

Jiménez Herrero, Luis M. (1997), Desarrollo sostenible y ecología económica, Síntesis, España.

Jiménez Martínez, Alfonso (1998), Desarrollo turístico y sustentabilidad: el caso de México, Porrúa, México.

Laborde, Pierre (1991), "Tourisme littoral et environnement, aménagement et protection" en Fourneau, Francis y Manuel Marchena (eds.), Ordenación y desarrollo del turismo en España y en Francia. Aménagement et développement du tourisme en France et en Espagne, Ministerio de Obras Públicas y Transportes, Madrid, España.

Lee, Rosemary (1978), "El Turismo en América Latina: el comercio del subdesarrollo", en Antonio Benavides C. (coord.), Turismo y desarrollo, Cuadernos de los centros regionales, Centro Regional de Antropología e Historia del Sureste, SEP-INAH, México, pp. 9-13.

Martín, Rosario; Xavier Aranda y Rosa Cibeira (1999), "Papel y viabilidad de fórmulas asociativas para el desarrollo de proyectos turísticos fundados en la sostenibilidad", en Román Rodríguez González, Alcides Dos Santos Caldas y José Mascarenhas Bisnieto (coords.) Desarrollo local y regional en Iberoamérica. Actas del Seminario Internacional sobre Perspectivas de Desarrollo en Iberoamérica, Universidad de Santiago de Compostela, España.

OMT (2001), Tourism 2020 vision. Volume 7: Global Forecasts and profiles of market segment, World Tourism Organisation, Madrid, España.

OMT (2002), Tourism Highlights, Organización Mundial del Turismo, Madrid, España.

OMT (2003), Tourism Highlights, Organización Mundial del Turismo, Madrid, España. 
Pearce, Douglas (1992), “Alternative Tourism: Concepts, Classifications, and Questions", en Smith y Eadington (eds.), Tourism Alternatives. Potentials and Problems in the Development of Tourism, University of Pennsylvania Press, Philadelphia, EUA, pp. 15-18.

Pimienta Muñiz, Manuel (1999), "Desarrollo sostenible: viabilidad de los indicadores de sostenibilidad en la planificación territorial”, en Román Rodríguez González, Alcides Dos Santos Caldas y José Mascarenhas Bisnieto (coords.), Desarrollo local y regional en Iberoamérica. Actas del Seminario Internacional sobre Perspectivas de Desarrollo en Iberoamérica, Universidad de Santiago de Compostela, España.

Piñera Ramírez, David (1994), Visión histórica de la Frontera Norte de México, (t. I y II), Universidad Autónoma de Baja California, Kino/El Mexicano, México.

Sánchez Zepeda, Leandro (2000), La industria vitivinícola en Baja California, Reporte de investigación, Facultad de Economía, Universidad Autónoma de Baja California, Tijuana, B.C., México.

Santos Solla, Xosé M. (1999), "Reflexións en torno ó papel do turismo no desenvolvimiento local”, en Román Rodríguez González, Alcides Dos Santos Caldas y José Mascarenhas Bisnieto (coords.), Desarrollo local y regional en Iberoamérica. Actas del Seminario Internacional sobre Perspectivas de Desarrollo en Iberoamérica, Universidad de Santiago de Compostela, España.

SeCtur (2001), Programa Nacional de Turismo 2001-2006, Secretaría de Turismo, México.

SECTUR (2002), Compendio estadístico del turismo en México 2002, Secretaría de Turismo, México.

SECTUR (2003), Compendio estadístico del turismo en México 2002, Secretaría de Turismo, México. 
SeCture (2003), Indicadores turísticos para Baja California, Secretaría de Turismo del Estado, Tijuana, B.c., México.

Sen, Amartya (2000), Desarrollo y libertad, Planeta, México.

Smil, Vaclav (1993), Global Ecology. Environmental Change and Social Flexibility. Rutledge, New York, EUA.

Smith Valene, L. y William R. Eadington (eds.) (1992), Tourism Alternatives. Potentials and Problems in the Development of Tourism, University of Pennsylvania Press, Philadelphia, EUA.

Swarbrooke, John (1998), Sustainable Tourism Management. CABI, Oxford.

The Body Shop Internacional, en <http:/www.laneta.apc.org/ mazunte/home.htm>, 21 de octubre de 2003.

Urry, John (1994), The Tourist Gaze. Leisure and Travel in Contemporary Societies. SAGE, Londres, Inglaterra.

Vázquez Barquero, Antonio (1988), Desarrollo local. Una estrategia de creación de empleo. Ediciones Pirámide, Madrid.

Vera Rebollo, Fernando J. (coord.) (1997), Análisis territorial del turismo, Editorial Ariel, España.

Vera Rebollo, Fernando y Vicente Monfort Mir, (1994), “Agotamiento de modelos turísticos clásicos. Una estrategia territorial para la calificación: la experiencia de la comunidad Valenciana", en Estudios Turísticos, núm.123, Madrid, España, pp. 17-45.

Villa Sánchez, Sughei (2002), La competitividad en el sistema productivo local del vino en el Valle de Guadalupe, Tesis de Maestría en Desarrollo Regional, El Colegio de la Frontera Norte, Tijuana, México.

Wall, Geoffrey (1997), "Is ecotourism sustainable?”, en Environmental Management vol. 21, núm. 4, pp. 483-491. (falta casa editora) 
Wilken Robertson, Michael (coord.) (1998), Desarrollo sustentable de las comunidades indígenas de Baja California, Instituto CUNA y FANCA, México.

Zeppel, Heather (1998), "Land and culture: sustainable tourism and indigenous peoples", en C. Michael Hall \& Alan A. Lew, Sustainable Tourism. A geographical perspective, Prentice Hall, London, pp.60-74.

Enviado: 7 de abril de 2003. Reenviado: 6 de noviembre de 2003. Aceptado: 26 de noviembre de 2003. 